\title{
Formation of homocitrulline during heating of milk
}

\author{
By ALI A. M. METWALLI*, WIM L. LAMMERS \\ AND MARTINUS A. J. S. VAN BOEKEL† \\ Department of Food Science, Wageningen Agricultural University, PO Box 8129, \\ NL-6700 EV Wageningen, The Netherlands
}

(Received 1\% November 199\% and accepted for publication 24 February 1998)

\begin{abstract}
Summary. Homocitrulline arises from the reaction between cyanate and the $\epsilon$-amino group of lysine residues; in milk, cyanate derives from heat-induced urea breakdown. Since homocitrulline levels were unknown in heated milk, its formation was studied in the temperature range $100-150{ }^{\circ} \mathrm{C}$. Firstly, an analysis method based on ionexchange chromatography using an amino acid analyser was developed. Homocitrulline, liberated from milk protein by enzymic hydrolysis, was eluted well separated from other amino acids and could be readily distinguished using this technique. Secondly, homocitrulline levels were determined for various timetemperature combinations in samples of milk, milk to which $10 \mathrm{~mm}$-urea had been added, and milk that was made urea-free. No homocitrulline was formed in urea-free milk, while homocitrulline formation was stimulated by urea addition. Upon prolonged heating, we found extensive subsequent breakdown of homocitrulline. The kinetics of homocitrulline formation was quite complicated, but an approximation was possible as the initial formation reaction could be modelled using zero order reaction kinetics. The apparent activation energy for homocitrulline formation was estimated at $\sim 90 \mathrm{~kJ} / \mathrm{mol}$. In general, the levels of homocitrulline to be expected in heated milk appeared to be quite low: $\sim 0.3 \mathrm{~mm}$ in in-bottle sterilized milk, and $<0.01 \mathrm{~mm}$ in UHT sterilized milk.
\end{abstract}

Heating causes all kinds of chemical changes in milk, protein being particularly affected. Amino acid residues can react with themselves (e.g. lysinoalanine formation, isopeptide formation, S-S exchange, racemization), as well as with milk components such as lactose (Maillard reaction) and urea. Reactions of urea have been summarized in a previous paper (Metwalli et al. 1996), and one of these reactions is the transformation of urea into (iso)cyanate, which can subsequently react with the $\epsilon$ amino group of lysine residues to form homocitrulline (Fig. 1). The effect of heating on homocitrulline formation may be twofold: firstly, heating induces the formation of (iso)cyanate from urea, and secondly, the formation of homocitrulline itself may be accelerated by heating (Annan \& Manson, 1981). Formation of homocitrulline is also possible under physiological conditions, for example from the reaction of casein with urea in which isocyanate is present (Manson, 1962), of ribonuclease with urea (Stark et al. 1960), of cyanate with pepsinogen and pepsin (Rimon \& Perlmann, 1968)

\footnotetext{
* Permanent address: Department of Dairying, Faculty of Agriculture, University of El-Minia, El-Minia, Egypt.

$\dagger$ For correspondence.
} 


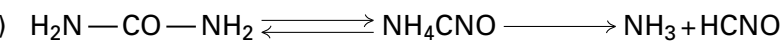

(b) $\mathrm{HCNO}+\mathrm{R}-\left(\mathrm{CH}_{2}\right)_{4}-\mathrm{NH}_{2} \longrightarrow \mathrm{R}-\left(\mathrm{CH}_{2}\right)_{4}-\mathrm{N}-\mathrm{C}-\mathrm{NH}_{2}$

| ||

(c) $\mathrm{HCNO}+\mathrm{H}_{2} \mathrm{O} \longrightarrow \mathrm{NH}_{3}+\mathrm{CO}_{2}$

$\mathrm{HO}$

Fig. 1. (a) Formation of (iso)cyanate (HCNO) from urea, $(b)$ formation of homocitrulline from cyanate and lysine residues and $(c)$ decomposition of cyanate into ammonia and carbon dioxide. $\mathrm{R}$ represents a protein chain.

and of haemoglobin and leucocyte proteins in the bodies of patients suffering from uraemia (Kraus et al. 1991, 1994; Trepanier et al. 1996).

The presence of homocitrulline in milk products could be important for two reasons. Firstly, the positive effect of urea on heat stability could be due to formation of homocitrulline (Fox et al. 1980; Sweetsur \& Muir, 1981; Shalabi \& Fox, 1982; Metwalli \& van Boekel, 1996a). The reason why formation of homocitrulline would improve heat stability was discussed recently in relation to other changes having an effect on heat stability (Metwalli \& van Boekel, 1996a). The second aspect is that consumption of dairy products containing homocitrulline would lead to excretion of homocitrulline in the urine (Gerritsen et al. 1963; Evered \& Vadgama, 1983). This excretion could interfere with the use of endogenous homocitrulline levels as an indicator of certain metabolic diseases.

These two aspects make it relevant to study homocitrulline formation in heated milk in more detail. Homocitrulline can be detected by chromatographic methods such as HPLC (Koshiishi et al. 1990) and amino acid analysis (Stark et al. 1960). Hydrolysis of the protein is necessary to liberate homocitrulline; when this was carried out by acid hydrolysis in $6 \mathrm{M}-\mathrm{HCl}$, Stark et al. (1960) reported that $28 \%$ of the homocitrulline was converted to lysine. Chromatographic methods pose some problems owing to the interference of the other amino acids present in much larger amounts (Koshiishi et al. 1990). Immunochemical detection in the intact protein is another possibility (Kraus et al. 1991), but requires the availability of specific antibodies. All in all, currently available methods do not seem not very suitable for analysing milk products containing homocitrulline, so we developed a method for analysing homocitrulline by amino acid analyser in the presence of other amino acids, after enzymic hydrolysis of the protein. Little is known about the actual level of homocitrulline in heated milk products. Gerritsen et al. (1963) reported values of $5-10 \mu \mathrm{g} / \mathrm{ml}$ in 'canned-liquid modified milk preparations' without specifying the composition of the milk product or the heat treatment given. An additional sterilization of these products resulted in a level of $33 \mu \mathrm{g} / \mathrm{ml}$. Manson et al. (1985) could not confirm such results in heating experiments at $90^{\circ} \mathrm{C}$. Manson \& Annan (1984) concluded that the significance of the formation of homocitrulline from urea in heated milk is likely to be limited. However, information on homocitrulline levels in sterilized milk products is just not available. Some preliminary results have been reported for milk heated at $140{ }^{\circ} \mathrm{C}$ (Metwalli et al. 1996; Metwalli \& van Boekel, $1996 b)$. Here we report more extensively on the determination and kineties of formation of homocitrulline in heated milk. 
MATERIALS AND METHODS

\section{Materials}

Urea and pepsin (EC 3.4.23.1) were obtained from Merck (D-64293 Darmstadt 1, Germany) and urease (EC 3.5.1.5) from Boehringer (D-68305 Mannheim, Germany). Thymol and mycolysis (from Streptomyces griseus; EC 3.4.24.31) were obtained from Fluka (CH-9470 Buchs, Switzerland), prolidase (EC 3.4.13.9) and amino acid standard solutions from Sigma (St Louis, MO 63178, USA), leucine aminopeptidase (EC 3.4.11.1; $2000 \mathrm{U} / \mathrm{ml}$ ) from Serva (D-69042 Heidelberg 1, Germany). Homocitrulline was obtained from ICN (Costa Mesa, CA 92626, USA), and glutamine and norleucine from Pierce (Rockford, IL 61105, USA).

\section{Milk samples}

Bulk milk was obtained from the University Farm and a single batch used for all experiments. The natural level of urea in this batch of milk was 5 mu. Fat was removed by centrifugation to an overall fat content of $<0 \cdot 1 \mathrm{~g} / \mathrm{l}$. Urea-free milk was produced by incubating $1 \mathrm{mg}$ pure urease with $100 \mathrm{ml}$ milk at $37^{\circ} \mathrm{C}$ for $1.5 \mathrm{~h}$. The absence of urea was checked by determining the urea concentration. Owing to the formation of ammonia from urea, the $\mathrm{pH}$ needed to be readjusted to $6 \cdot 6$. Ureaenriched milk was produced by adding solid urea to milk to a level of $10 \mathrm{~mm}$ (so that the final level of urea was $15 \mathrm{~mm})$.

\section{Heat treatment}

Milk $(3 \mathrm{ml})$ was heated at various time-temperature combinations in stainless steel tubes. After heating, the tubes were immediately cooled in ice water. The reported heating times include the heating-up period, estimated at $2 \mathrm{~min}$.

\section{Enzymic digestion of milk protein}

The protein in milk samples was enzymically hydrolysed according to a method described by Schmitz et al. (1976). A milk sample ( $\sim 0 \cdot 18 \mathrm{~g}$ milk, corresponding to $\sim 6 \mathrm{mg}$ protein) was brought to $\mathrm{pH} 2$ using $1.2 \mathrm{ml} 0.02 \mathrm{M}-\mathrm{HCl}$. Pepsin solution $(0.3 \mathrm{ml} ; 25 \mathrm{FIP}$ units $/ \mathrm{ml}$ in $0.02 \mathrm{M}-\mathrm{HCl})$ was added together with a thymol crystal and the mixture incubated at $40{ }^{\circ} \mathrm{C}$ for $24 \mathrm{~h}$ with shaking in a water bath. Then the $\mathrm{pH}$ was raised to 8.2 with $\sim 0.025 \mathrm{ml} 1 \mathrm{M}-\mathrm{NaOH}$ and $0.5 \mathrm{ml}$ Pronase E solution $(6.75 \mathrm{U} / \mathrm{ml}$ in $1 \mathrm{M}$-sodium borate buffer $\mathrm{pH} 8 \cdot 2$ ) was added and the mixture incubated at $40^{\circ} \mathrm{C}$ for $24 \mathrm{~h}$. Then $1 \mathrm{ml}$ prolidase solution $(5 \mathrm{U} / \mathrm{ml}$ in 1 m-sodium borate buffer, $\mathrm{pH} 8 \cdot 2)$ and $1 \mathrm{ml}$ leucine aminopeptidase solution $(5 \mathrm{U} / \mathrm{ml}$ in $1 \mathrm{M}$-sodium borate buffer, $\mathrm{pH}$ $8 \cdot 2$ ) were added and the whole incubated at $40{ }^{\circ} \mathrm{C}$ for $24 \mathrm{~h}$. Finally the volume was adjusted to $5 \mathrm{ml}$ with water and the solution filtered through a disposable $0.45 \mu \mathrm{m}$ filter (Schleicher \& Schuell, D-37582 Dassel, Germany). The filtered solution was stored at $-20{ }^{\circ} \mathrm{C}$ until analysis.

\section{Analysis of homocitrulline by amino acid analyser}

The amino acid analyses were performed using an ion-exchange chromatography system (Biochrom 20 Amino Acid Analyzer; Pharmacia Biotech (Biochrom) Ltd, Cambridge CB4 4FJ, UK). Amino acids were post-column derivatized with ninhydrin and detected by absorbance at $570 \mathrm{~nm}$. The temperature of the reaction coil was $135^{\circ} \mathrm{C}$. Buffers and ninhydrin reagent were obtained from Pharmacia Biotech (Ultropac Chemicals). Two systems were used, one with a high resolution cation- 
Table 1. Elution programme, elution buffers and column temperature used with the amino acid analyser giving optimal separation of homocitrulline using a $\mathrm{Na}^{+}$column

$\begin{array}{cccc}\text { Step no. } & \text { Time, min:s } & \text { Temperature, }{ }^{\circ} \mathrm{C} & \text { Buffer } \\ 1 & 9: 30 & 37 & 0 \cdot 2 \text { M-sodium citrate, } \mathrm{pH} 3 \cdot 2 \\ 2 & 14: 00 & 63 & 0 \cdot 2 \text { M-sodium citrate, } \mathrm{pH} 4 \cdot 25 \\ 3 & 12: 00 & 65 & 1 \cdot 2 \text { M-sodium citrate, } \mathrm{pH} 6 \cdot 45 \\ 4 & 10: 00 & 90 & 1 \cdot 2 \mathrm{M} \text {-sodium citrate, } \mathrm{pH} 6 \cdot 45 \\ 5 & 9: 00 & 90 & 1 \cdot 2 \mathrm{M} \text {-sodium citrate, } \mathrm{pH} 6 \cdot 45 \\ 6 & 10: 00 & 80 & 0 \cdot 4 \text { M-sodium hydroxide } \\ 7 & 16: 00 & 80 & 0 \cdot 2 \text { M-sodium citrate, } \mathrm{pH} 3 \cdot 2 \\ 8 & 6: 00 & 37 & 0 \cdot 2 \text { M-sodium citrate, } \mathrm{pH} 3 \cdot 2\end{array}$

Table 2. Elution programme, elutions and column temperatures used with the amino acid analyser giving optimal separation of homocitrulline using a $\mathrm{Li}^{+}$column

\begin{tabular}{|c|c|c|c|}
\hline Step no. & Time, $\min : \mathrm{s}$ & Temperature, ${ }^{\circ} \mathrm{C}$ & Buffer \\
\hline 1 & $16: 15$ & 34 & $0 \cdot 2$ м-lithium citrate $\mathrm{A}, \mathrm{pH} 2 \cdot 8$ \\
\hline 2 & $21: 00$ & 34 & $0 \cdot 3$ m-lithium citrate $\mathrm{B}, \mathrm{pH} 3 \cdot 0$ \\
\hline 3 & $12: 00$ & 34 & 0.5 m-lithium citrate CII, $\mathrm{pH} 3 \cdot 15$ \\
\hline 4 & $28: 00$ & 70 & 0.5 м-lithium citrate CII, $\mathrm{pH} 3 \cdot 15$ \\
\hline 5 & $21: 00$ & 74 & 0.9 м-lithium citrate DII, $\mathrm{pH} 3.45$ \\
\hline 6 & $36: 00$ & 74 & 1.65 м-lithium citrate, $\mathrm{pH} 3.55$ \\
\hline 7 & $20: 00$ & 80 & 1.65 м-lithium citrate, $\mathrm{pH} 3.55$ \\
\hline 8 & $8: 00$ & 80 & $0 \cdot 3$ m-lithium hydroxide solution \\
\hline 9 & $5: 00$ & 80 & $0 \cdot 2$ m-lithium citrate $\mathrm{A}, \mathrm{pH} 2 \cdot 8$ \\
\hline 10 & $35: 00$ & 34 & $0 \cdot 2$ m-lithium citrate $\mathrm{A}, \mathrm{pH} 2 \cdot 8$ \\
\hline 11 & $11: 00$ & 34 & $0 \cdot 2$ м-lithium citrate $\mathrm{A}, \mathrm{pH} 2 \cdot 8$ \\
\hline
\end{tabular}

exchange column (Ultropac 8 cation-exchange resin, particle size $9 \cdot 0 \pm 0.5 \mu \mathrm{m}$, column dimensions $200 \times 4 \cdot 6 \mathrm{~mm}$ ) in the sodium form, and one in the lithium form. The elution buffers and programmes used are given in Tables 1 and 2 for the sodium and lithium columns respectively. The buffer flow rates were 25 and $20 \mathrm{ml} / \mathrm{h}$ for the $\mathrm{Na}^{+}$and $\mathrm{Li}^{+}$columns respectively; the ninhydrin reagent flow rate was $20 \mathrm{ml} / \mathrm{h}$. Calibration of the $\mathrm{Na}^{+}$column was performed with a standard amino acid solution (Sigma, AA-S-18) plus homocitrulline, with norleucine as internal standard. Amino acids were loaded at $10 \mathrm{nmol}$ (except cystine, which was loaded at $5 \mathrm{nmol}$ ). Calibration of the $\mathrm{Li}^{+}$column was with a standard amino acid solution (Sigma A7407 and A-6282) plus glutamine and homocitrulline, with norleucine as internal standard. Amino acids were loaded at $5 \mathrm{nmol}$ (except cystine, which was loaded at $2.5 \mathrm{nmol}$ ). Hydrolysed milk sample was loaded in the amino acid analyser at $20 \mu \mathrm{l}$ when using the $\mathrm{Na}^{+}$column, and at $50 \mu \mathrm{l}$ in the case of the $\mathrm{Li}^{+}$column.

RESULTS

\section{Determination of homocitrulline}

Homocitrulline was determined by amino acid analysis with a column using one of two types of counter ions, either $\mathrm{Na}^{+}$or $\mathrm{Li}^{+}$, with each form requiring its own elution buffers and programme (Tables 1 and 2). With both types of column, a satisfactory separation was achieved without serious interference from other amino acids. Fig. $2(a)$ shows a chromatogram of amino acid standards plus homocitrulline with the norleucine internal standard for the $\mathrm{Na}^{+}$column; Fig. 3 $(a)$ shows the 

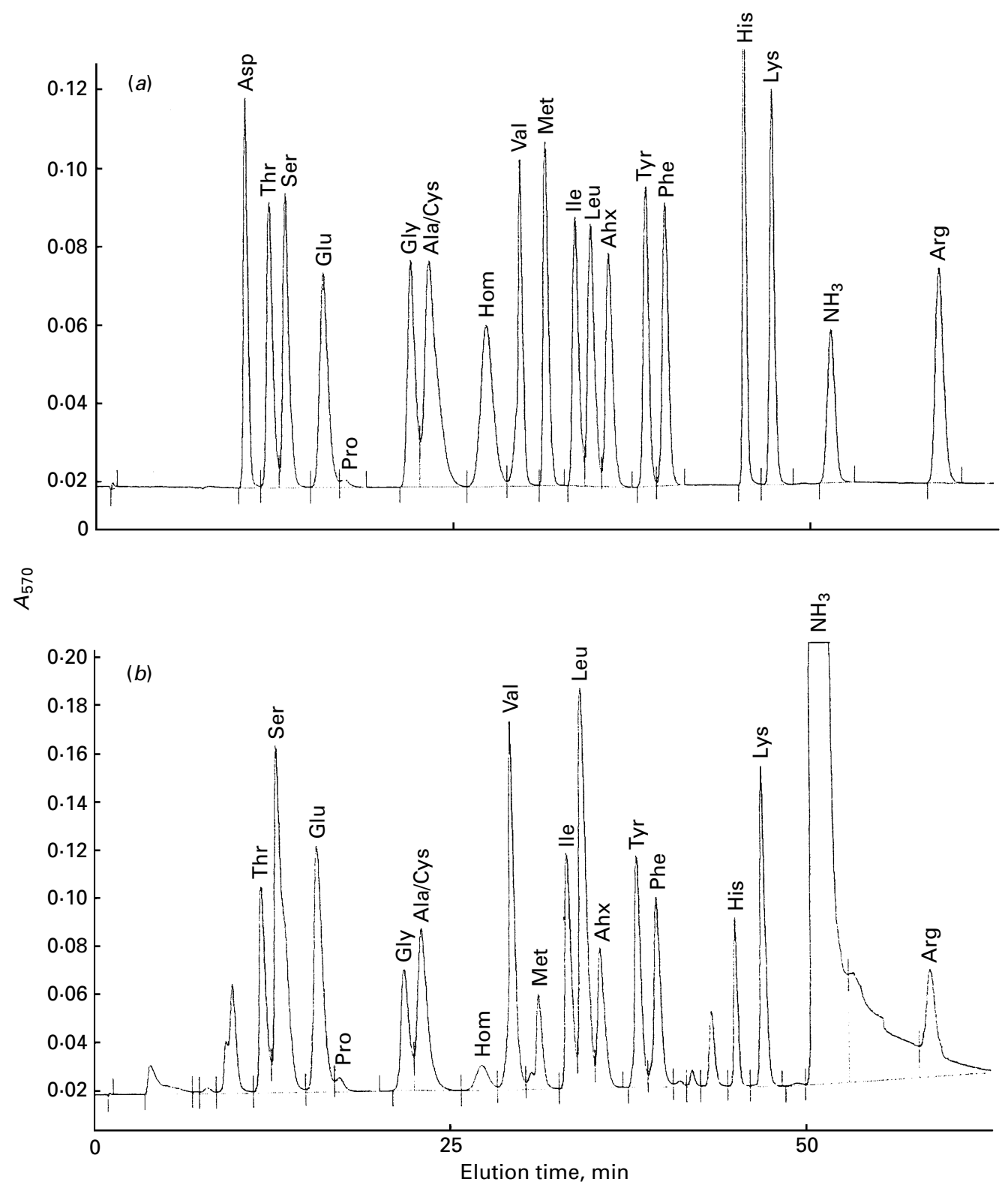

Fig. 2. Chromatograms of $(a)$ amino acids standards and $(b)$ a heated enzymically hydrolysed milk sample obtained from an amino acid analyser using a $\mathrm{Na}^{+}$column. Amino acids were detected at $570 \mathrm{~nm}$ after post-column derivatization with ninhydrin. Elution time of homocitrulline was $27 \cdot 4 \mathrm{~min}$. Ahx, norleucine; Hom, homocitrulline.

chromatogram for the $\mathrm{Li}^{+}$column. For practical reasons, the $\mathrm{Li}^{+}$column was used in most of the experiments. When analysing enzymically digested milk protein (heated or unheated), we noted that the neutral and acidic amino acids were not well separated on the $\mathrm{Li}^{+}$column (Fig. $3 b$ ) while the separation seemed to be satisfactory with the $\mathrm{Na}^{+}$column (Fig. $2 b$ ). However, for unheated milk samples, the calculated contents of the amino acids that were well separated in the chromatogram (retention time $>50 \mathrm{~min}$ ) compared well with the concentrations expected from the average 


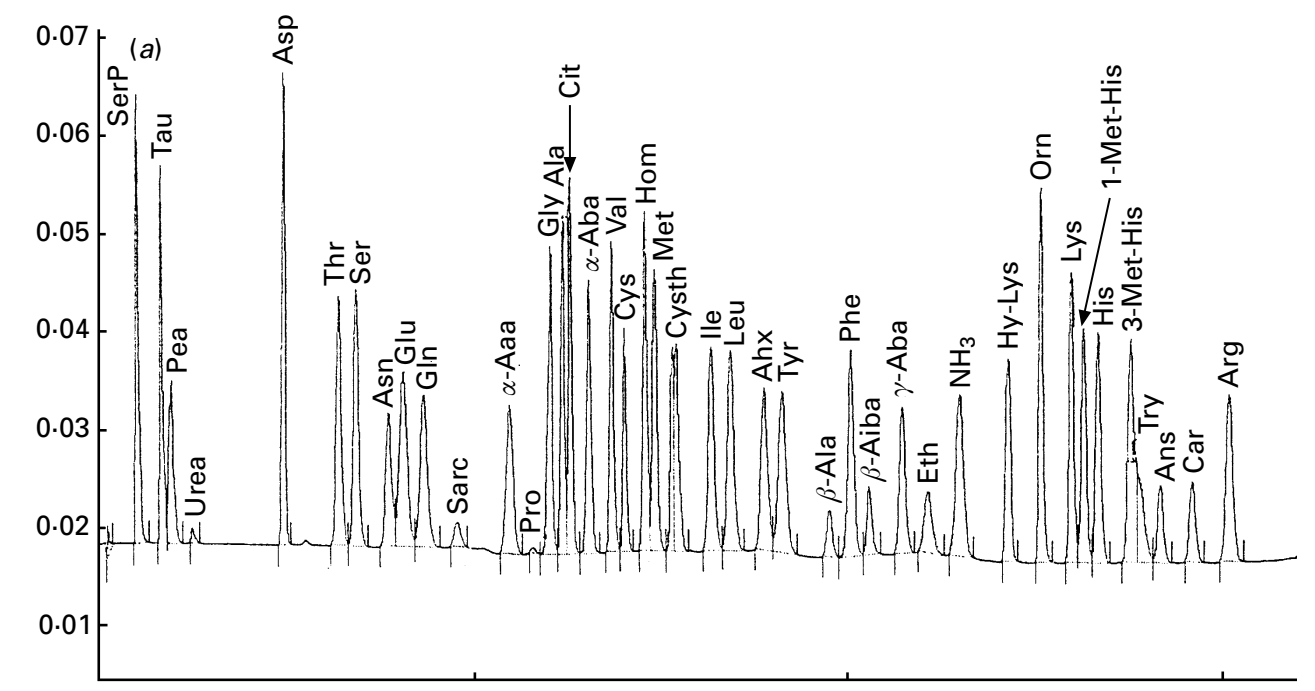

$\stackrel{\substack{6 \\ \leftarrow}}{0}$

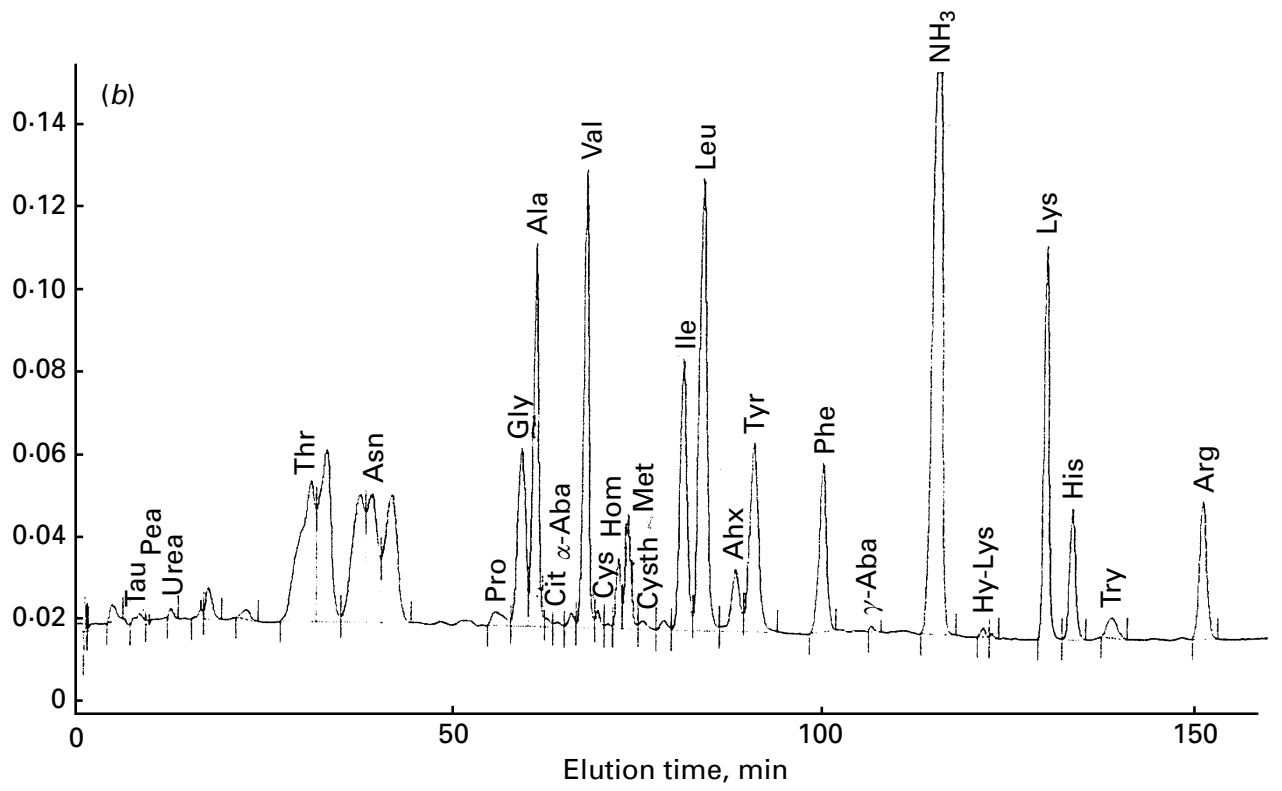

Fig. 3. Chromatograms of $(a)$ amino acids standards and $(b)$ a heated enzymically hydrolysed milk sample obtained from an amino acid analyser using a $\mathrm{Li}^{+}$column. Amino acids were detected at $570 \mathrm{~nm}$ after post-column derivatization with ninhydrin. Elution time of homocitrulline was $74 \mathrm{~min}$. Ahx, norleucine; Hom, homocitrulline; SerP, phosphoserine; Pea, phosphoethanolamine; Cit, citrulline; $\alpha$-Aba, $\alpha$-aminobutyric acid; $\gamma$-Aba, $\gamma$-aminobutyric acid; Cysth, cystathionine; Hy-Lys, hydroxylysine; Sare, sarcosine; $\alpha$-Aaa, $\alpha$-aminoadipic acid; $\beta$-Ala; $\beta$-alanine; $\beta$-Aiba, $\beta$-aminoisobutyric acid; Eth, ethanolamine; 1-Met-His; 1-methylhistidine; 3-Met-His, 3-methylhistidine; Ans, Anserine; Car, carnitine.

composition of milk proteins (Walstra \& Jenness, 1984). (It may be noted that the proline peaks were quite small; this is because proline should be measured at 440 rather than $570 \mathrm{~nm}$.) Hence the hydrolysis must have been nearly complete. Since homocitrulline eluted in the region where peaks were well separated, this 

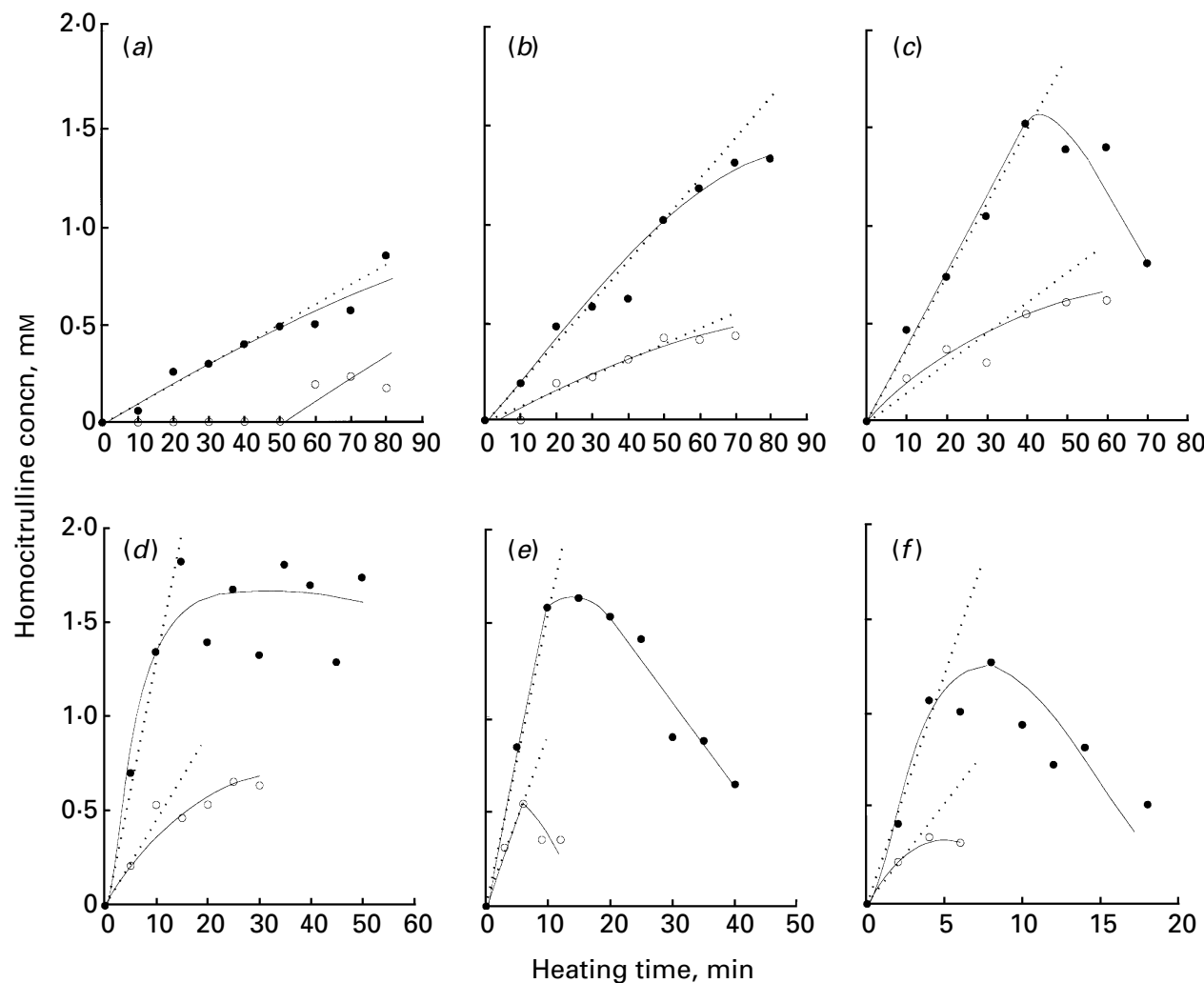

Fig. 4. Formation of homocitrulline in milk heated at $(a) 100,(b) 110,(c) 120,(d) 130,(e) 140$ and $(f)$ $150{ }^{\circ} \mathrm{C}$ : $\mathrm{O}$, without addition of urea; $\boldsymbol{O}$, with $10 \mathrm{~mm}$-urea added. $\cdots$, Zero order kinetics approximation for the formation of homocitrulline; —_, interpolation of experimental results.

phenomenon was not considered a problem. The CV for determination of amino acids (including the enzymic hydrolysis procedure) was estimated to be $3-4 \%$ for milk samples; however, milk samples to which urea had been added appeared to be subject to larger variations, with CV of $5-10 \%$.

The limit of detection for homocitrulline in milk was estimated to be $0.005 \mathrm{~mm}$.

\section{Effect of heating on homocitrulline formation}

Homocitrulline formation due to heating was studied in three types of milk: normal raw milk without any addition (containing 5 mu-urea as its natural level), raw milk to which $10 \mathrm{~mm}$-urea had been added (to give a total of $15 \mathrm{~mm}$-urea), and urea-free raw milk.

Heated urea-free milk did not contain any homocitrulline (at least not at levels above the detection limit). As is well known, milk with added urea was more heat stable than milk without (e.g. Metwalli \& van Boekel, 1996a); therefore, milk with added urea could be heated for a longer time than milk. Milk to which urea had been added contained more homocitrulline than milk that contained urea at only its natural level (Fig. 4). As can be seen from Fig. 4, homocitrulline was clearly also subject to breakdown, especially at the higher temperatures. These results confirm the preliminary results obtained at $140{ }^{\circ} \mathrm{C}$ and reported previously (Metwalli et al. 1996; Metwalli \& van Boekel, 1996b). Unfortunately, the results for $130{ }^{\circ} \mathrm{C}$ varied considerably. This was so not only for homocitrulline but also for the other amino acids; probably the hydrolysis procedure was the cause of the erroneous results. 
DISCUSSION

\section{Determination of homocitrulline}

The chromatograms obtained showed that it is quite possible to determine homocitrulline in heated milk samples, with columns in both the $\mathrm{Na}^{+}$and $\mathrm{Li}^{+}$forms. One of the problems with the techniques for homocitrulline determination previously reported (Stark et al. 1960; Manson et al. 1985) has been the interference from other amino acids present in much higher amounts in milk. We seem to have overcome this problem using the present approach. Analysis using the $\mathrm{Na}^{+}$column had three advantages over that with the $\mathrm{Li}^{+}$column: the total analysis time was shorter, all amino acids of interest were separated and there was no interference from (supposedly) small peptides in the region of neutral and acidic amino acids. The main advantage of using the $\mathrm{Li}^{+}$column is that many more amino acids could be determined simultaneously: for instance, it was possible to determine asparagine, glutamine, threonine and serine with the $\mathrm{Li}^{+}$but not with the $\mathrm{Na}^{+}$column .

The interference in the region of the neutral and acidic amino acids on the $\mathrm{Li}^{+}$ column was presumably due to presence of small peptides, which would indicate that enzymic hydrolysis was not complete. However, the fact that the amounts of amino acids outside the interference region corresponded to the amounts expected from the average composition of milk implied that hydrolysis was nearly complete. The alternative for enzymic hydrolysis would be chemical hydrolysis in $6 \mathrm{~m}$ - $\mathrm{HCl}$ but this has the disadvantage that at least $28 \%$ of the homocitrulline is destroyed (Stark et al. 1960).

We have no explanation for the observation that the analysis method was less precise when urea was added to milk. Possibly the presence of urea had some effect on the activity of the enzymes used in the hydrolysis procedure, although we consider this improbable because of the rather low concentration of urea $(5$ and $15 \mathrm{~mm})$.

\section{Homocitrulline formation}

The fact that homocitrulline was not formed in the absence of urea confirms that urea, via cyanate, is one of the precursors (the other being the $\epsilon$-amino group of lysine residues). It was also clear that the amounts of homocitrulline formed were not large, at the most $0.5 \mathrm{~mm}$ in milk containing $5 \mathrm{~mm}$-urea, the average amount in milk (Walstra \& Jenness, 1984). This amount of homocitrulline corresponds to $\sim 2 \%$ of the lysine residues. The observed decrease in homocitrulline levels in extensively heated milk samples could be due to two reasons, the first being that homocitrulline was broken down again, the second that enzymic release of homocitrulline was hampered because of heat-induced changes in protein. If the second explanation were true, one would also expect a similar decrease in other amino acids, and that appeared not to be the case (results not shown). Some amino acids remained at about the same levels regardless of heating intensity, while the levels of others decreased (notably lysine and arginine) because they were also subject to reactions other than formation of homocitrulline (the Maillard reaction being important). Moreover, homocitrulline levels increased at first, while levels of lysine and arginine decreased from the beginning. All this suggests that homocitrulline is indeed subject to heatinduced breakdown after its initial formation.

The kinetics of homocitrulline formation appeared to be complex. Firstly, the cyanate precursor is not present in raw milk and must be formed first from urea. This is the explanation for the induction period found at 100 and $110^{\circ} \mathrm{C}$ for milk without 


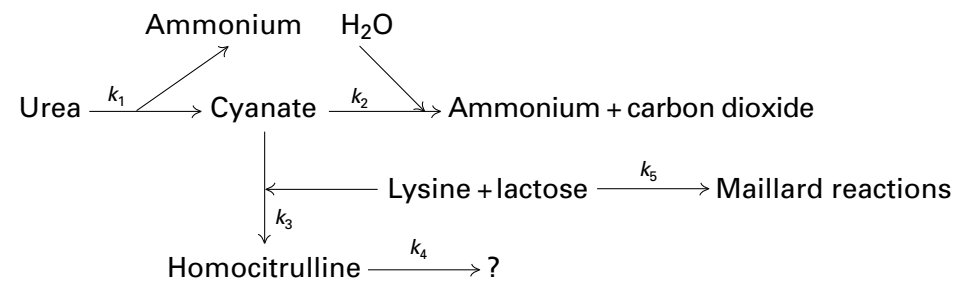

Fig. 5. Kinetic model for the reaction network of homocitrulline formation and breakdown: $k_{x}$ represents rate constants for the various reaction steps; ? indicates unknown breakdown of homocitrulline.

added urea (Fig. 4). When urea was added, cyanate formation was stimulated and the induction period disappeared; the same reasoning applies to the disappearance of the induction period at higher temperatures, when cyanate formation was also stimulated. Furthermore, cyanate is only an intermediate in urea degradation. Metwalli et al. (1996) found that in heated milk roughly two moles of ammonia were formed with simultaneous destruction of one mole of urea (cf. Fig. 1). However, one cannot conclude from this that urea is quantitatively converted to ammonia, because ammonia in heated milk is also produced as a result of deamidation of protein. From results reported by Metwalli \& van Boekel (1998) for deamidation of caseinate, it can be deduced that at $140{ }^{\circ} \mathrm{C} 20-30 \%$ of the amount of ammonia formed is due to deamidation. It is thus indeed possible that cyanate is present in measurable concentrations; presumably, it occurs as a steady state intermediate at a certain concentration (probably quite low, say $<1 \mathrm{~mm}$ ). However, it will be formed continuously as long as urea is present. As mentioned above, heating itself has also an effect on cyanate formation and breakdown: cyanate formation from urea is promoted at higher temperatures (Stark et al. 1960), but presumably its breakdown to ammonia and carbon dioxide is also promoted by increased temperature. The second precursor, lysine, is also subject to other reactions, notably the Maillard reaction, and this reaction leads to a higher lysine loss than that due to homocitrulline formation (Berg \& van Boekel, 1994). There is thus a competition for lysine residues between cyanate and lactose (which, incidentally, provides an explanation for the stabilizing effect of urea on heat stability, as discussed by Metwalli \& van Boekel, $1996 a$ ). A (simplified) kinetic model for homocitrulline formation is presented in Fig. 5. These various reaction routes make it impossible to derive the five relevant reaction rate constants for formation of homocitrulline from the present results. A full kinetic analysis would require measurement of formation and breakdown of cyanate and breakdown of lysine. The analysis method applied here allows determination of lysine contents (even that of urea and ammonia in the case of the $\mathrm{Li}^{+}$column) but not that of cyanate. In order to extract information on the kinetics of homocitrulline formation, we used the following approach. It was noted that at all temperatures studied the initial formation of homocitrulline was more or less linear (Fig. 4), hence zero order reaction kinetics could be applied for the initial phases. Zero order reaction rate constants could thus be derived (except for milk without added urea at $100{ }^{\circ} \mathrm{C}$ because of the considerable induction period, ef. Fig. 4). It should be realized that these rate constants comprise also the formation of cyanate and are thus pseudo rate constants. The Arrhenius equation was used to derive the temperature dependence (Fig. 6). However, the actual estimation of the pre-exponential factor and activation energy was carried out in a one step procedure, i.e. without derivation of rate constants, as this improves the confidence intervals 


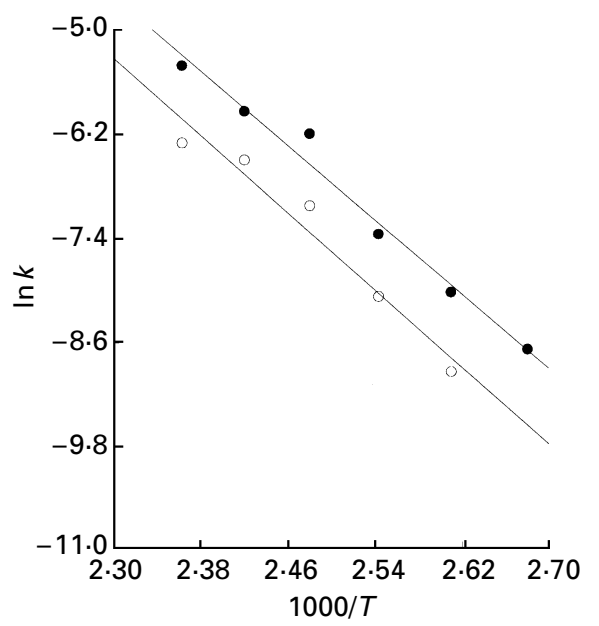

Fig. 6. Arrhenius plot for formation of homocitrulline in milk: $\bigcirc$, without addition of urea; $\boldsymbol{0}$, with 10 mu-urea added, as approximated by zero order reaction kinetics; $k$, reaction rate; $T$, absolute temperature.

Table 3. Estimated kinetic characteristics for formation of homocitrulline in heated milk using a zero order approximation

(Values are means $\pm 95 \%$ confidence intervals)

\begin{tabular}{lcc}
\multicolumn{1}{c}{ Type of milk } & $\begin{array}{c}\text { Activation energy, } \\
\mathrm{kJ} / \mathrm{mol}\end{array}$ & $\begin{array}{c}\text { Pre-exponential factor, } \\
\mathrm{mm} / \mathrm{s}\end{array}$ \\
Raw milk & $92 \cdot 1 \pm 13 \cdot 3$ & $2 \cdot 9 \times 10^{10} \pm 4 \cdot 2 \times 10^{9}$ \\
Raw milk + 10 mu-urea & $92.5 \pm 8.4$ & $8.4 \times 10^{10} \pm 7 \cdot 4 \times 10^{9}$
\end{tabular}

(Van Boekel, 1996). These results are given in Table 3. No statistical difference was found in the temperature dependence of homocitrulline formation in milk and milk with added urea. This would imply that the temperature dependence of cyanate and homocitrulline formation was about the same. (Of course, the actual amount of cyanate, and hence that of homocitrulline did depend on the urea level, as can be seen in Fig. 4.)

In conclusion, it can be stated that the amounts of homocitrulline formed in heated milk are quite limited. The actual amount depends on the natural level of urea in milk, a higher level of urea resulting in a higher homocitrulline level. The amounts to be expected (as estimated from the temperature dependence) in in-bottle sterilized milk (e.g. heated at $120^{\circ} \mathrm{C}$ for $15 \mathrm{~min}$ ) are in the order of $0.3 \mathrm{~mm}$, and in UHT milk $\left(145{ }^{\circ} \mathrm{C}\right.$ for $\left.2 \mathrm{~s}\right)<0.01 \mathrm{~mm}$. In order to predict homocitrulline formation in other milk products, a more elaborate study of the kinetics of homocitrulline formation would be necessary. This would require measurement of the levels of urea, ammonia, cyanate, homocitrulline and lysine in heated milk, and subsequent estimation of the relevant rate constants via multiresponse modelling (Van Boekel, 1996).

\section{REFERENCES}

Annan, W. D. \& Manson, W. 1981 The production of lysinoalanine and related substances during processing of proteins. Food Chemistry 6 255-261

Berg, H. E. \& van Boekel, M. A. J. S. 1994 Degradation of lactose during heating of milk. 1. Reaction pathways. Netherlands Milk and Dairy Journal 48 157-175 
Evered, D. F. \& Vadgama, J. V. 1983 Absorption of homocitrulline from the gastrointestinal tract. British Journal of Nutrition $4935-42$

Fox, P. F., Nash, B. M., Horan, T. J., O'Brien, J. \& Morrissey, P. A. 1980 Effect of selected amides on heat-induced changes in milk. Journal of Dairy Research 47 211-219

Gerritsen, T., Vaughn, J. G. \& Waisman, H. A. 1963 The origin of homocitrulline in the urine of infants. Archives of Biochemistry and Biophysics 100 298-301

Koshitshi, I., Kobori, Y. \& Imanari, T. 1990 Determination of citrulline and homocitrulline by highperformance liquid chromatography with post-column derivatization. Journal of Chromatography: Biomedical Applications $\mathbf{5 3 2} 37-44$

Kraus, L. M., Elberger, A. J., Handorf, C. R., Pabst, M. J. \& Kraus, A. P. 1994 Urea-derived cyanate forms $\epsilon$-amino-carbamoyl-lysine (homocitrulline) in leukocyte proteins in patients with end-stage renal disease on peritoneal dialysis. Journal of Laboratory and Clinical Medicine 123 882-891

Kraus, L. M., Miyamura, S., Pecha, B. R. \& Kraus, A. P. 1991 Carbamoylation of hemoglobin in uremic patients determined by antibody specific for homocitrulline (carbamoylated $\epsilon$-N-lysine). Molecular Immunology 28 459-464

Manson, W. 1962 The effect upon casein of aqueous solutions of urea. Biochimica et Biophysica Acta 63 $515-517$

Manson, W. \& Annan, W. D. 1984 Aspects of the chemistry of heated milk. Report of the Hannah Research Institute, $198377-84$

Manson, W., Carolan, T. \& Annan, W. D. 1985 Products of the heat-promoted reaction between urea and the protein fraction of bovine milk. Journal of Dairy Research 52 401-407

Metwalli, A. A. M., Metwalli, N. H. \& van Boekel, M. A. J. S. 1996 Effect of urea on heat-induced changes in milk. Netherlands Milk and Dairy Journal 50 427-457

Metwalli, A. A. M. \& van Boekel, M. A. J. S. 1996 a Effect of urea on heat coagulation of milk. Netherlands Milk and Dairy Journal $\mathbf{5 0} 459-476$

Metwalli, A. A. M. \& van Boekel, M. A. J. S. $1996 b$ Effect of urea on heat coagulation of milk. In Heat Treatments and Alternative Methods, Proceedings of the IDF Symposium held in Vienna, 1995, pp. 335-340. Brussels: International Dairy Federation

Metwalli, A. A. M. \& van Boekel, M. A. J.S. 1998 On the kinetics of heat-induced deamidation and breakdown of caseinate. Food Chemistry 61 53-61

Rimon, S. \& Perlmann, G. E. 1968 Carbamylation of pepsinogen and pepsin. Journal of Biological Chemistry $2433566-3572$

Schmitz, I., Zahn, H., Klostermeyer, H., Rabbel, K. \& Watanabe, K. 1976 [On the occurrence of isopeptide bonds in heated milk protein.] Zeitschrift für Lebensmittel-Untersuchung und -Forschung $\mathbf{1 6 0}$ $377-381$

Shalabi, S. I. \& Fox, P. F. 1982 Heat stability of milk: influence of modification of lysine and arginine on the heat stability-pH profile. Journal of Dairy Research 49 607-617

Stark, G. R., Stein, W. H. \& Moore, S. 1960 Reactions of the cyanate present in aqueous urea with amino acids and proteins. Journal of Biological Chemistry 235 3177-3181

Sweetsur, A. W. M. \& Muir, D. D. 1981 Role of cyanate ions in the urea-induced stabilization of the caseinate complex in skim-milk. Journal of Dairy Research 48 163-166

Trepanier, D. J., Thibert, R. J., Draisey, T. F. \& Caines, P. S. 1996 Carbamylation of erythrocyte membrane proteins: an in vitro and in vivo study. Clinical Biochemistry 29 347-355

VAN Boekel, M. A. J. S. 1996 Statistical aspects of kinetic modeling for food science problems. Journal of Food Science 61 477-485, 489

Walstra, P. \& Jenness, R. 1984 Dairy Chemistry and Physics. New York: Wiley 